\title{
Pergolide Mesylate
}

National Cancer Institute

\section{Source}

National Cancer Institute. Pergolide Mesylate. NCI Thesaurus. Code C47665.

A semi-synthetic ergot derivative and a dopamine agonist with antiparkinson property. Pergolide mesylate binds to and activates dopamine receptor subtypes D1 and D2, resulting in prolactin secretion inhibition, transient increase in serum concentration of growth hormone, and decrease in serum concentration of luteinizing hormone. Direct stimulation of postsynaptic dopamine receptors in the nigrostriatal system, may account for this agent's antiparkinson activity. 